
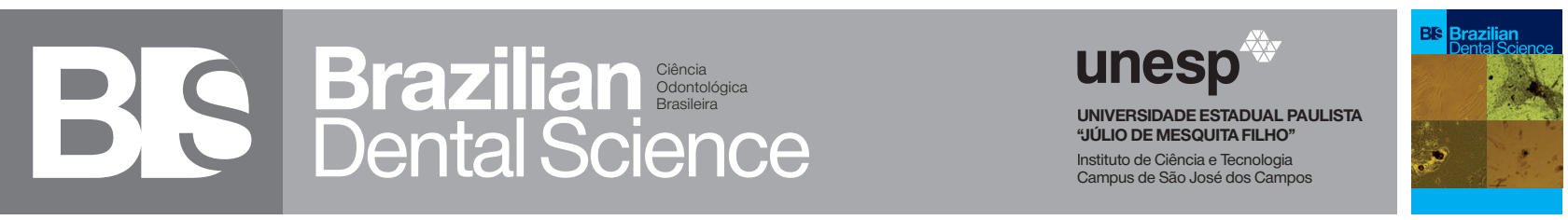

\title{
Botulinum toxin-A injections as therapy for chronic painful post- traumatic trigeminal neuropathy: case report
}

Injeções de toxina botulínica-A como terapia para dor neuropática trigeminal pós-traumática crônica: relato de caso

Giancarlo de la Torre CANALES $^{1}$, Rodrigo Lorenzi POLUHA ${ }^{1}$, Dyna Mara FERREIRA ${ }^{1}$, Juliana STUGINSKI-BARBOSA ${ }^{1}$, Paulo Rodrigues CONTI $^{1}$

1 - Department of Prosthodontics - Bauru School of Dentistry - University of São Paulo - Bauru - Brazil.

\begin{abstract}
Painful post-traumatic trigeminal neuropathy (PTTN) involves spontaneous and evoked pain, of moderate to severe intensity, continuous and described as burning or shooting. The first line treatment is pharmacological. However, botulinum toxin - A (BoNT-A) can be used when medications cannot control pain. This article describes the use of BoNT-A in a case of PTTN refractory to conventional pharmacological treatment. A 44-year-old male patient presented with an 8-years history of pain in the lower left second molar region. Pain was burning, lasting for seconds, with multiple pain episodes per day. Diagnosis hypothesis was PTTN. After no improvement with conventional pharmacological treatment, injections of BoNT-A were elected. Somatosensory assessment showed a significant reduction in visual analog scale for touch, cold and pinprick sensitivity. Likewise, patient's impression of change in pain significantly improved after BoNT-A injections. Our results suggest that BoNT-A could be used as a treatment for PTTN refractory to conventional treatments.
\end{abstract}

\section{KEYWORDS}

Post-traumatic trigeminal neuropathy; Trigeminal neuropathic pain; Botulinum toxin.

\section{RESUMO}

A neuropatia trigeminal pós-traumática dolorosa (PTTN) envolve dor espontânea e evocada, de intensidade moderada a grave, contínua e descrita como queimante ou lascinante. O tratamento de primeira linha é farmacológico. No entanto, a toxina botulínica - A (BoNT-A) pode ser usada quando os medicamentos não conseguem controlar a dor. Este artigo descreve o uso da BoNT-A em um caso de PTTN refratário ao tratamento farmacológico convencional. Paciente de sexo masculino, 44 anos, com 8 anos de dor na região do segundo molar inferior esquerdo. A dor foi descrita como queimante, com duração de segundos e com vários episódios por dia. A hipótese de diagnóstico foi PTTN. Após nenhuma melhora com o tratamento farmacológico convencional, as injeções de BoNT-A foram eleitas. A avaliação somatossensorial mostrou uma redução significativa na escala visual analógica para sensibilidade ao toque, frio e picada após BoNT-A. Da mesma forma, a impressão de mudança do paciente na dor melhorou significativamente após as injeções de BoNT-A. Nossos resultados sugerem que o BoNT-A poderia ser usada como tratamento para PTTN refratário a tratamentos convencionais.

\section{PALAVRAS-CHAVE}

Neuropatia trigeminal pós-traumática; Dor neuropática trigêminal; Toxina botulínica. 


\section{INTRODUCTION}

$\mathrm{T}$ he term painful post-traumatic trigeminal neuropathy (PTTN) embraces all neuropathics pain of traumatic origin affecting the trigeminal nerve ${ }^{1}$. PTTN is described as unilateral or bilateral facial or oral pain following and caused by trauma to the trigeminal nerve(s), with other symptoms and/or clinical signs of trigeminal nerve dysfunction. It is five times more common in women than in men (mean age 45.5 years old); most frequently affecting the territory of third trigeminal branch; with no face side preference ( $46 \%$ left side, $49 \%$ right side, and $5 \%$ bilateral) and with extra and intraoral presentations [1].

PTTN may result from a wide variety of nerves injury including macrotrauma at craniofacial area (eg. fight, vehicle accident) or minor injuries from dental interventions (eg. third molar surgery, routine exodontia, root canal treatment, placement of dental implants) [1]. The clinical phenotype may involve combinations of spontaneous and evoked pain of a trigger zone, of moderate to severe intensity, unilateral, continuous, described as burning or shooting with positive (e.g. dysesthesia) and negative symptomatology (e.g. numbness) [1].

The first line treatments for any neuropathic pain including PTTN is well known to be pharmacologic [2]. Several classes of medications have been recommended for this condition including tricyclic antidepressants, calcium channel blockers, serotonin and norepinephrine reuptake inhibitors. Notwithstanding, the major problems of long-lasting pharmacologic therapy for this condition are systemic side effects [2]. In PTTN, the response rates for this therapeutic approach used to be lower (about 11\%) when compared with other types of neuropathic pain [2]. Therefore, other treatment options have been proposed to control pain in refractory patients, such as local injections of medications including lidocaine and, recently, botulinum toxin - A (BoNT-A) [3].
Botulinum toxin - A (BoNT-A) is the fermentation product of Clostridium botulinum, a Gram - positive anaerobic bacteria in the spore forming; such as toxin, selectively enters neurons and inhibits synaptic neurotransmitter exocytosis. Local paralysis with peripheral BoNT-A doses is the basis for treatment of neuromuscular disorders. In addition, pericranial injections of BoNT-A could alleviate the symptoms of some forms of chronic migraine [4].

Systematic review [5] and clinical trials [6] about BoNT-A showed its clinical use on neuropathic pain and concluded that BoNT-A could be a promissing treatment for refractory cases, due to its favorable risk-to-benefit ratio. In addition to blocking the release of acetylcholine, there is consistent evidence that BoNT-A inhibit the release of glutamate, substance $P$ and calcitonin gene-related peptide (CGRP) and that may, inhibit the expression of the transient receptor potential vanilloid 1 (TRPV1) [6, 7]. Thus, utilizing BoNT-A in PTTN is a logical extension of its clinical usefullness. Notwithstanding, as far as we know, there are no clinical trials assessing the effects of BoNT-A in PTTN. A case report was published, addressing the possitive effects of BoNT-A for this condition [8].

Therefore, the aim of this article is to describe the use of botulinum toxin $\mathrm{A}$ as a peripheral therapeutic agent in a patient with persistent painful post-traumatic trigeminal neuropathy, refractory to conventional pharmacologic treatment.

\section{CASE REPORT}

A 44-year-old male patient with a history of pain in the left inferior second molar region was admitted at the University of Bauru-Sao Paulo TMD and Orofacial Pain Clinic. He described the pain as continuos and burning one. Pain intensity was 8 in the Visual Analogue Scale - VAS (0-10), worsted while eating, brushing his teeth or working out, started four months after an exodontia 
of the left first inferior molar and lasted for 8 years in the same region. In clinical and tomographic examination, no alterations were observed that could explain his symptoms. The Diagnostic Neuropatic Pain Questionnaire (DN4) scored for neuropathic pain.

After anamnesis, qualitative sensory tests (QualST) were performed. In short, QualsT evaluated the sensitivity to touch, cold and pinprick stimuli on the test site compared with the contralateral site. The touch stimulus was applied with a Q-tip in a single stroke over 1-2 $\mathrm{cm}$ of skin. The cold stimulus was applied with a stainless-steel dental spatula (kept cool in ice water, approximately $0{ }^{\circ} \mathrm{C}$ ) and the pinprick stimulus was applied with a dental examination probe with moderate force on the skin both stimulus for 1-2 s. The patient was asked to report hypersensitivity, hyposensitivity or normosensitivity to the stimuli on the test site compared with the control contralateral site and to report pain intensity after each exam with Visual Analogue Scale (VAS). The results indicated hypersensitive for touch and pinprick in the region. The diagnosis hypothesis was PTTN.

An inferior alveolar blockade was done with lidocaine; which resulted in reduction in pain intensity (VAS: 0). Thus, topical application of $0.025 \%$ capsaicin (four times a day for 5 minutes) and nortriptyline $10 \mathrm{mg}$ (once daily) were prescribed. A reduction in pain intensity was reported by the patient; however, it was not significant. Therefore, nortryptiline dose was increased to $25 \mathrm{mg}$ (once daily); however, medication was not tolerated (tachycardia and dizziness); consequently, pregabalin $75 \mathrm{mg}$ was prescribed (2 times daily). After a month, patient reported drowsiness, as medication adverse effect and stopped the medication use. Pain returned with the same intensity and quality. Our third approach was oxcarbazepin 300mg 2 times daily, with parcial reduction in pain features over follow-ups during a period of 8 months. Unfortunately, patient did not come for posterior follow ups and returned to our clinic two years later without using any medication and presenting the same pain features of the beginning of the treatment. Due to the low ratio of pain improvement and adverse effects with previous pharmacotherapy, submucosal injections of onabotulinum toxin $\mathrm{A}$ in the painful region were elected.

Injection sites were determined based on pain location. The patient recognized one clear area for his pain, mapped through QualsT; which was in the buccal gingiva apical to the left first molar region, extended over to the second premolar and molar ipsilateral. A trial of 100 units of onabotulinum toxin A (BOTOX ${ }^{\circledR}$; Allergan Inc., Irvine, CA) was diluted in $2.0 \mathrm{~mL}$ saline solution. Ten injections of $0.10 \mathrm{~mL}$ at approximately 0,05 $\mathrm{mm}$ depth were performed in total in the QualsT mapped painful region, corresponding to 5 units of toxin per injection (50U in total).

To evaluate the effects of onabotulinum toxin A, subjective pain intensity and somatossensory changes were assessed using the VAS and the QualsT (Figure 1). Perception of treatment changes was assessed by the Patient Global Impression of Change (PGIC) and VAS using pain diary (Table 1). No other concomitant treatments were indicated to the patient.

Table 1 - Means of the Patient Global Impression of Change (PGIC) scale applied in different periods

\begin{tabular}{|l|lllll|}
\hline & 1W & 2W & 3W & 2M & 3M \\
\hline No change (or condition has got worse) & & & & & \\
\hline Almost the same, hardly any change at all & $\mathrm{X}$ & & & & \\
\hline A little better, but no noticeable change & & & & \\
$\begin{array}{c}\text { Somewhat better, but the change has not } \\
\text { made any real difference }\end{array}$ & & & & \\
\hline $\begin{array}{c}\text { Moderately better, and a slight but noticea- } \\
\text { ble change }\end{array}$ & & $X$ & $X$ & \\
$\begin{array}{c}\text { Better, and a definite improvement that has } \\
\text { made a real and worthwhile difference }\end{array}$ & $\mathrm{X}$ & & & $\mathrm{X}$ \\
\hline $\begin{array}{c}\text { A great deal better, and a considerable im- } \\
\text { provement that has made all the difference }\end{array}$ & & & & \\
\hline
\end{tabular}

W: week; M: month. 


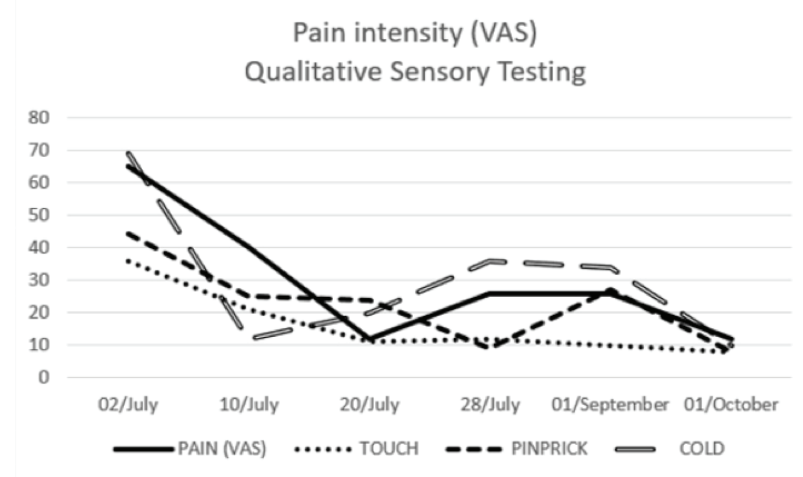

Figure 1- Pain intensity in Qualitative Sensory Testing (QualST). Data $(\mathrm{mm})$ presented in different periods.

Subjective pain achieved significant reduction after the second week of onabotulinum toxin A injections and continue improving until the third month follow up. Somatossensory assessment showed significant reduction in VAS scale for touch, cold and pinprick sensitivity in all follow-ups until the 3rd month evaluation; however, despite the improvement in subjective pain associated to QualsT, the patient conserved functional gain. Likewise, patient's impression of change in his pain was significantly improved since the second week and until the $3^{\text {rd }}$ month follow up. There were no side effects reported by the patient. The benefit provided by the onabotulinum toxin A was perceived as significant by the patient also in the next two months after our last follow up (5th month after onabotulinum toxin A injections). In the 6-month follow-up session, pain intensity and quality recurred. Notwithstanding patien's improvement, a second BoNT-A injection could not be performed, because the patient abandoned the treatment.

\section{DISCUSSION}

In the described case, intraoral injection of BoNT-A decreased pain intensity in a patient with post-traumatic trigeminal neuropathy. This result is in accordance with a previously published case report that used botulinum toxin intraorally for the same neuropathic problem and achieved similar results [8].

Currently, preclinical models showed that local injections of BoNT-A exert its antinociceptive activity by preventing the sensory transmitter release in periphery; inhibing the release of various nociceptive mediators, such as substance $\mathrm{P}$, glutamate, CGRP and the expression TRPV1 [6,7], which would justify its used for peripheral neuropatic pain. Notwithstanding, a recent double-blind randomized placebocontrolled trial assessed the sustained efficacy and neurogenic inflammation response of 2 subcutaneous administrations of BoNT-A by measuring neuropeptide levels (calcitonin generelated peptide and substance $\mathrm{P}$ ) from skin biopsy and quantitative sensory test (QST) in patients with peripheral neuropathic pain including posttraumatic nerve lesion. Results showed that BoNT-A improved pain intensity for a long period of time in patients with mechanical allodynia although peripheral neuropeptides levels did not modify3. BoNT-A might act preferentially through central mechanisms of action, possibly through retrograde axonal transport [6]. In addition, recent data demonstrated axonal transport for BoNT-A antinociceptive action [7] and evidence of toxin enzymatic activity in brainstem and spinal cord sensory regions suggesting that BoNT-A inhibits central pain transmission [8], mechanism that could explain the possitive results obtained in this case report.

As mention above, in Attal et al., [3] study, response to BoNT-A was predicted by the presence of mechanical allodynia and was suggested that the best responder profiles to BoNT-A were characterized by preservation of nociceptive input due to the correlation found between the preservation of thermal deficits and the response to BoNT-A. It is important to highlight, that BoNT-A was particularly effective in reducing sensitivity to touch in our patient. In addtion subjective pain report related to QualST tests were reduced.

Different botulinum toxin administration protocols have been reported for the treatment of neuropathic pain; however, to date, there is no consensus about the ideal dosing to achieve a proper therapeutic effect. A recent systematic review [9] reported that in cases of trigeminal neuralgia, doses ranged from 25 to 100 units divided into 1 to 20 numbers of injections in 
diferents sites along the distribution of the trigeminal nerve could be used. Since there are few data about doses for PTTN, we decided to be conservative about this issue. Eventhough we used 50 units in total in a unique injection; which is a lower dose when compared to Herrero et al., [8]. Pain presented a significant reduction and lasted longer as well.

BoNT-A therapeutic effects in our patient lasted for 5 months; therefore, it is important to question the number of repeated BoNT-A injections required to sustain the relief of pain. Unfortunately, patient denied a second application and we could not be able to assess multiple injection effects. Literature showed that repeated injections are useful in increasing therapeutic benefits and promoting a continuous pain-free state $[3,8]$.

The guidelines of the Neuropathic Pain Special Interest Group (NeuPSIG) stated the use of BoNT-A as probably effective and categorized it as third line approach "level C" for PTTN [10] which means that this treatment is not the first treatment choice for this kind of neuropathic pain, meanly due to the lack of consistent evidence coming from well designed clinical trials. Therefore, there is a need for clinical trials to assess this treatment effectiveness and safety. In addition, studies should be carried out to compare the minimum doses that are effective, to reduce posible adverse effects.

\section{CONCLUSIONS}

Our results suggest that botulinum toxin - A could be used as treatment for painful posttraumatic trigeminal neuropathy refractory to conventional pharmacotherapy. However, they should be analysed prudently; since there is paucity to assess the effectiveness and safety of single or repeated injections of botulinum toxin for neuropathic peripheral pain. We strongly recommend the evaluation of patient phenotype, to improve this treatment effects.

\section{REFERENCES}

1. Headache Classification Committee of the International Headache Society (IHS). The International Classification of Headache Disorders, 3rd edition. Cephalalgia. 2018;38(1):1-211. doi:10.1177/0333102417738202.

2. Finnerup NB, Attal N, Haroutounian S, McNicol E, BaronR, Dworkin R, etal. Pharmacotherapy for neuropathic pain in adults: a systematic review and metaanalysis. Lancet Neurol. 2015Feb;14(2):162-73. doi: 10.1016/S1474-4422(14)702510. Epub2015Jan7.

3. Attal N, de Andrade DC,Adam F, Ranoux D, Teixeira MJ, Galhardoni R, etal. Safety and efficacy of repeated injections of botulinum toxin Ain peripheral neuropathic pain (BOTNEP): arandomized, double-blind, placebo-controlled trial Lancet Neurol.2016 May;:15(6):555-65. doi:10.1016/S1474-4422(16)00017-X. Epub 2016 Mar2.

4. Hollanda L,Monteiro L,Melo A. Botulinum toxin type A for cephalic cutaneous allodynia in chronic migraine: A randomized, double-blinded, placebo-controlled trial. Neurol Int.2014 Dec 5;6(4):5133. doi: 10.4081/ni.2014.5133. eCollection 2014 0ct23.

5. Sandrini G, DelccoR, TassorelliC,SmaniaN, Tamburin S. Botulinumneurotoxin type $A$ for the treatment of pain: notjust in migraine and trigeminal neuralgia. JHeadachePain. 2017Dec;18(1):38. doi: 10.1186/s10194-017-0744-z. Epub 2017 Mar21.

6. Lora VR, Clemente-Napimoga JT,Abdalla HB,Macedo CG, Canales GT,Barbosa CM. Botulinum toxin type A reduces inflammatory hypernociception induced by arthritis in the temporomandibular joint of rats. Toxicon. 2017 Apr;129:52-57.doi: 10.1016/.t.toxicon.2017.02.010. Epub2017 Feb 14.

7. Matakl,Bach-RojeckyL,Filipovic B,LackovićZZBehavioral and immunohistochemical evidence for central antinociceptive activity of botulinum toxin A. Neuroscience.2011 Jul 14;186:201-7. doi: 10.1016/j. neuroscience.2011.04.026. Epub2011 Apr 20.

8. Herrero Babiloni A, Kapos FP,Nixdorf DR. Intraoral administration of botulinum toxin for trigeminal neuropathic pain. Oral Surg Oral Med Oral Pathol Oral Radiol. 2016 Jun;121(6):e148-53. doi: 10.1016/.j0000.2016.03.013.Epub 2016 Mar 23.

9. Morra ME, Elgebaly A, Elmaraezy A, Khali AM, Altibi AMA, Vu T,etal. Therapeutic efficacy and safety of Botulinum Toxin A Therapy in Trigeminal Neuralgia: a systematic review and meta-analysis of randomized controlled trials. J Headache Pain.2016 Dec;17(1):63. doi:10.1186/s10194-016-0651-8. Epub 2016 Jul 5.

10. Cruccu G, Truini A.A review of Neuropathic Pain: From Guidelines to Clinical Practice.Pain Ther.2017 Dec;6(Suppl 1):35-42. doi:10.1007/s40122-017-0087-0. Epub2017 Nov24. 